\title{
Elotuzumab for the treatment of multiple myeloma
}

\author{
Yucai Wang ${ }^{1 \dagger}$, Larysa Sanchez ${ }^{1 \dagger}$, David S. Siegel ${ }^{2}$ and Michael L. Wang ${ }^{3^{*}}$
}

\begin{abstract}
Elotuzumab is one of the first two monoclonal antibodies that gained FDA approval for the treatment of multiple myeloma (MM). It targets SLAMF7, which is highly expressed in normal plasma and MM cells as well as natural killer (NK) cells. Elotuzumab demonstrated significant anti-myeloma activity in preclinical studies, and its mechanisms of action include mediating antibody-dependent cell-mediated cytotoxicity, enhancing cytotoxicity of NK cells, and inhibiting MM cell interaction with bone marrow stromal cells. In clinical trials, elotuzumab in combination with immunomodulatory drugs and proteasome inhibitors has demonstrated an excellent efficacy and safety profile in treating MM.
\end{abstract}

\section{Background}

The paradigm of multiple myeloma (MM) therapy has changed dramatically in the past two decades. Immunomodulatory drugs (IMiDs) including thalidomide and lenalidomide and proteasome inhibitors (PIs) such as bortezomib and carfilzomib emerged as novel agents with high efficacy [1-3] and greatly improved overall survival (OS) of patients with MM [4]. Despite these significant advances, most patients still relapse and eventually become treatment-resistant. The median OS of patients with disease double refractory to thalidomide/lenalidomide and bortezomib was only 9 months [5]. Recently, a plethora of new agents have emerged as effective therapies, including new generation of PIs (carfilzomib, ixazomib) and IMiD (pomalidomide), histone deacetylase inhibitors (panobinostat, vorinostat), and monoclonal antibodies (daratumumab, elotuzumab), among others, which will hopefully further improve MM treatment outcomes [6]. While the CD20 antibody rituximab plays a pivotal role in lymphoma treatment, efficacious monoclonal antibodies have been long awaited in MM. In November of 2015, the US Food and Drug Administration (FDA) approved the CD38 antibody daratumumab and SLAMF7 antibody elotuzumab for the treatment of MM. In this article, we review

\footnotetext{
*Correspondence: miwang@mdanderson.org

${ }^{\dagger}$ Equal contributors

${ }^{3}$ Department of Lymphoma/Myeloma, Division of Cancer Medicine, The University of Texas M. D. Anderson Cancer Center, 1515 Holcombe Blvd., Unit 429, Houston, TX 77030, USA

Full list of author information is available at the end of the article
}

the development and mechanisms of action of elotuzumab and summarize available data from preclinical and clinical studies.

\section{SLAMF7 as a therapeutic target in MM}

In an attempt to identify potential new therapeutic targets in MM, Hsi and colleagues [7] first took a subtractive hybridization approach to subtract naïve $B$ cell complementary DNA (cDNA) from the memory B cell and plasma cell cDNA library. The remaining genes that were selectively expressed in plasma cells were screened for structural/functional classification and the potential for cell surface localization. SLAMF7 was one of the genes identified to be highly expressed in plasma cells and to encode a cell-surface protein against which antibodies could potentially be developed.

SLAMF7, also known as CS1 (CD2 subunit 1), belongs to the signaling lymphocytic activation molecule (SLAM) family of cell surface receptors that are important for immunomodulation $[8,9]$. It was previously recognized as a NK cell surface receptor that was critical for NK cell activation [10-12]. Gene expression profiling revealed that SLAMF7 expression was restricted to leukocytes, primarily plasma cells, and NK cells, and absent in other normal tissues [7]. In addition, SLAMF7 was highly expressed in plasma cells from healthy donors, patients with monoclonal gammopathy of undetermined significance (MGUS), smoldering multiple myeloma (SMM), and MM regardless of molecular subtype [7]. 
Most SLAM family receptors, including SLAMF7, are self-ligands $[8,9]$. Upon receptor engagement, the presence or absence of adaptor protein in the cell dictates stimulatory or inhibitory effect, respectively [8]. While most SLAM family receptors use SLAM-associated protein (SAP) and EWSFli1-activated transcript-2 (EAT-2) as adaptors, it appears that SLAMF7 only recruits EAT$2[8,9]$. In NK cells, SLAMF7 interacts with EAT-2 and activates PI3K and PLC- $\gamma$ signaling pathways, thereby exerts a positive effect on NK cell function $[9,12]$. In the absence of EAT-2, SLAMF7 mediates an inhibitory effect [8]. Although plasma cells do not express EAT-2, SLAMF7 may utilize other mechanisms to promote myeloma cell growth and survival. Studies have shown that SLAMF7-mediated signaling is important for the interaction between myeloma cells and their adhesion to bone marrow stromal cells (BMSCs) and can activate ERK1/2, STAT3, and AKT pathways to promote survival $[13,14]$. The expression profile, cell surface localization, and the cellular functions make SLAMF7 an excellent therapeutic target in MM.

\section{Elotuzumab development and preclinical studies in $\mathbf{M M}$}

Hsi and colleagues [7] initially developed two mouse monoclonal antibodies, MuLuc63 (IgG2a) and MuLuc90 (IgG2b), that recognize the extracellular domain of SLAMF7. Both antibodies exhibited in vivo anti-myeloma activity in a L363 xenograft model. Because MuLuc63 was significantly more potent, it was selected for humanization [15]. HuLuc63, the fully humanized version of MuLuc63, exhibited significant anti-tumor activity in L363, OPM2, and MM1S xenograft models $[7,13,15]$. This antibody was later named elotuzumab.

The mechanisms of action of elotuzumab include mediating antibody-dependent cell-mediated cytotoxicity (ADCC) [7, 13], enhancing NK cell cytotoxicity [16], and disrupting MM cell adhesion to BMSC [13] (Fig. 1). In vitro $A D C C$ studies showed that elotuzumab induced MM cell lysis by peripheral blood mononuclear cells (PBMCs) [13] and autologous or allogeneic NK cells [7]. Depletion of NK cells from PBMCs [13] or

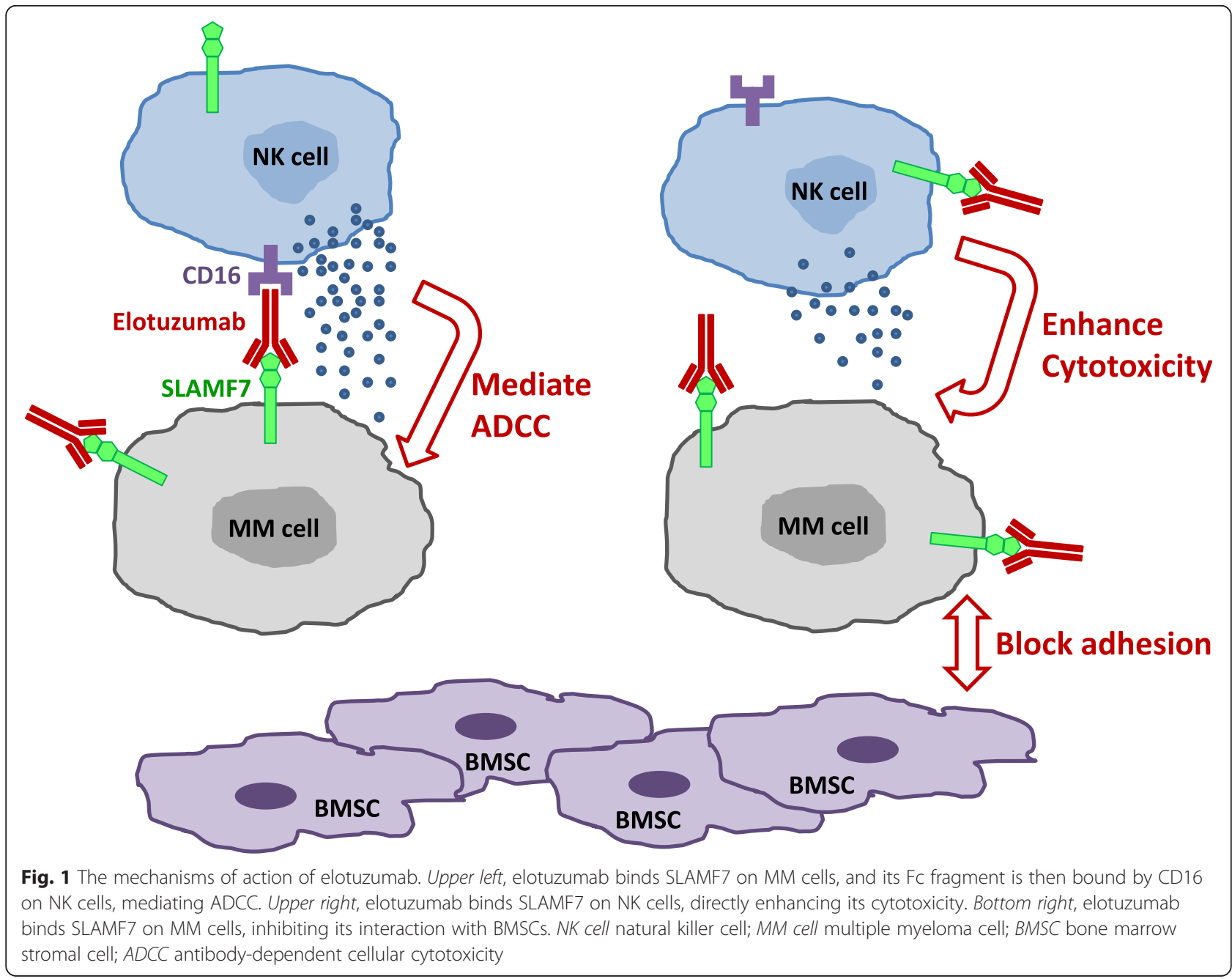


blocking the Fc receptor (CD16) on NK cells [7] significantly inhibited the ADCC activity. In the OPM2 xenograft model, altering the HuLuc63 affinity with CD16 affected its anti-myeloma activity accordingly, and depletion or suppressing the function of host NK cells also abolished its anti-myeloma activity. These studies suggest that NK cells are the dominant effectors that mediate elotuzumab-induced ADCC against MM cells. Collins et al. demonstrated that elotuzumab can also bind SLAMF7 on NK cells and enhance its cytotoxicity towards MM cells in an ADCC-independent manner [16]. Elotuzumab, as well as its G2M3 variant with defective CD16 binding, increased CD69 expression, IFN$\gamma$ production, and granzyme B $(\mathrm{GrB})$ secretion of NK cells, suggesting that elotuzumab can activate NK cells through SLAMF7 binding. Elotuzumab facilitated SLAMF7 interaction with EAT-2 and enhanced phosphorylation of ERK in NK cells, confirming a direct role of elotuzumab on NK cell activation through SLAMF7 ligation [16]. Interestingly, elotuzumab and its $\mathrm{F}(\mathrm{ab})_{2}{ }_{2}$ fragment can stabilize the interaction between SLAMF7 on NK cells and MM cells and enhance MM cell killing, again suggesting the presence of elotuzumab-induced ADCC-independent cytotoxicity of NK cells against MM cells [16]. Furthermore, Tai et al. showed that elotuzumab can inhibit MM cell adhesion to BMSCs and may overcome the stimulatory effects of BMSCs on MM growth and survival in coculture experiments [13], indicating that targeting myeloma-microenvironment interaction is an additional anti-myeloma mechanism of elotuzumab as summarized above.

While initial xenograft studies have demonstrated significant anti-myeloma activity of elotuzumab [7, 13], combination of elotuzumab with other agents appeared to have superior activities. Van Rhee and colleagues showed that elotuzumab in combination with bortezomib had better anti-tumor activity than either single agent alone in an OPM2 xenograft model [17]. Similarly, Balasa et al. demonstrated that adding lenalidomide enhanced the anti-myeloma activity of elotuzumab in the OPM2 xenograft model [18]. These studies provided the rationale for testing elotuzumab-containing combinational therapy for $\mathrm{MM}$ in clinical trials. Modulating NK cell-mediated ADCC by activating the CD137 receptor with an agonistic antibody or blocking killer immunoglobulin-like receptor (KIR)-mediated inhibitory signaling with lirilumab has been shown to enhance the anti-myeloma activity of elotuzumab [19, 20]. Preliminary ex vivo studies have shown that elotuzumab can enhance the cytotoxicity of ex vivo expanded NK (ENK) cells towards MM cells $[21,22]$. These combinational immunotherapies warrant further investigation.

\section{Elotuzumab for MM treatment in clinical trials}

Clinical trials of elotuzumab that have data reported are summarized in Table 1. The first-in-human study of elotuzumab was a phase 1 trial evaluating its safety, tolerability, pharmacokinetics, and pharmacodynamics [23]. Thirty-five patients with MM who had received at least two lines of therapy were enrolled, with a median age of 64.5 years and a median of 4.5 lines of therapy. Using a standard $3+3$ dose escalation approach, 34 patients were treated, with doses ranging from 0.5 to $20 \mathrm{mg} / \mathrm{kg}$. The maximum tolerated dose (MTD) was not reached with dose escalation up to the maximum planned dose (MPD). Common treatment-related adverse events (AEs) included chills, fatigue, pyrexia, cough, headache, anemia, nausea, and back pain, most of which were grade $1-2$. Only two grade $3-4$ AEs were attributed to elotuzumab, including one grade 3 hypersensitivity and one grade 4 acute renal failure. Transfusion reactions appeared common although most were grade $1-2$, necessitating a protocol amendment to include premedication before first infusion. Commonly seen $\mathrm{AE}$ with other anti-myeloma agents such as peripheral neuropathy with bortezomib and thalidomide were not observed with elotuzumab [24, 25]. SLAMF7 on bone marrow-derived MM cells was saturated at doses of 10 and $20 \mathrm{mg} / \mathrm{kg}$. After a median of four infusions at 2-week intervals, nine patients had stable disease (SD), but no objective response was observed. However, it should be noted that only three patients were treated at the dose that has been FDA approved $(10 \mathrm{mg} / \mathrm{kg})$.

Subsequent clinical studies have focused on elotuzumab in combination with other agents such as IMiDs and PIs. In the phase $1 \mathrm{~b}$ part of the 1703 study, elotuzumab at escalating doses $(5,10$, and $20 \mathrm{mg} / \mathrm{kg}$ ) was combined with lenalidomide and dexamethasone (Rd) for treatment of relapsed or refractory (RR) MM [26]. Twenty-nine patients were enrolled, with a median age of 60 and a median of 3 prior therapies. No doselimiting toxicity (DLT) was observed during dose escalation, and the $20 \mathrm{mg} / \mathrm{kg}$ cohort was expanded. Common AEs included fatigue, anemia, diarrhea, nausea, constipation, and neutropenia; most frequently reported grade 3-4 AEs were neutropenia (36 \%) and thrombocytopenia (21\%). Infusion reactions were observed in $89 \%$ of the patients, most of which were grade $1-2$. In the updated report, objective response rate (ORR) was $82 \%$ for the 28 treated patients, with $1(4 \%)$ complete response (CR), 12 (43\%) very good partial response (VGPR), and 10 (36 \%) partial response (PR) [27]. For the $20 \mathrm{mg} / \mathrm{kg}$ cohort (22 patients, treated until disease progression), median duration of response (DOR) has not been reached after a median follow-up of 16.4 months [26]. According to the updated report, the median progression-free survival (PFS) was 32.9 months overall [27]. 
Table 1 Major clinical trials of elotuzumab that have published data

\begin{tabular}{|c|c|c|c|c|c|c|c|}
\hline Study & NCT number (trial name) & Phase & $N$ & Regimen & ORR & PFS rate & $\begin{array}{l}\text { Median PFS } \\
\text { (months) }\end{array}$ \\
\hline Zonder 2012 [23] & $\begin{array}{l}\text { NCT00425347 } \\
\text { (HuLuc63-1701) }\end{array}$ & 1 & $35^{a}$ & Elotuzumab $(0.5-20$ mg/kg) & 0 & - & - \\
\hline Lonial 2012 [26, 27] & $\begin{array}{l}\text { NCT00742560 } \\
\text { (HuLuc63-1703) }\end{array}$ & $1 b$ & $29^{b}$ & Elotuzumab $(5-20 \mathrm{mg} / \mathrm{kg})+\mathrm{Rd}$ & $82 \%$ & - & 32.9 \\
\hline \multirow[t]{2}{*}{ Richardson 2015 [27] } & \multirow{2}{*}{$\begin{array}{l}\text { NCT00742560 } \\
\text { (HuLuc63-1703) }\end{array}$} & \multirow[t]{2}{*}{2} & 36 & Elotuzumab $(10 \mathrm{mg} / \mathrm{kg})+\mathrm{Rd}$ & $92 \%$ & & $32.5^{c}$ \\
\hline & & & 37 & Elotuzumab $(20 \mathrm{mg} / \mathrm{kg})+\mathrm{Rd}$ & $76 \%$ & & $25.0^{c}$ \\
\hline \multirow[t]{2}{*}{ Lonial 2015 [32] } & \multirow{2}{*}{$\begin{array}{l}\text { NCT01239797 } \\
\text { (ELOQUENT-2) }\end{array}$} & \multirow[t]{2}{*}{3} & 321 & Elotuzumab $(10 \mathrm{mg} / \mathrm{kg})+\mathrm{Rd}$ & $79 \%$ & 1-year $68 \%$, 2-year $41 \%$ & 19.4 \\
\hline & & & 325 & $\mathrm{Rd}$ & $66 \%$ & 1-year $57 \%, 2$-year $27 \%$ & 14.9 \\
\hline Mateos 2014 [34] & NCT01632150 & 2 & 40 & Elotuzumab $(10 \mathrm{mg} / \mathrm{kg})+\mathrm{TD}^{\mathrm{d}}$ & $40 \%$ & - & - \\
\hline Jakubowiak 2012 [35] & $\begin{array}{l}\text { NCT00726869 } \\
\text { (HuLuc63-1702) }\end{array}$ & 1 & 28 & Elotuzumab $(2.5-20 \mathrm{mg} / \mathrm{kg})+\mathrm{V}$ & $48 \%$ & & $9.46^{\mathrm{e}}$ \\
\hline \multirow{2}{*}{$\begin{array}{l}\text { Palumbo } 2015 \text { [38] } \\
\text { Jakubowiak } 2016 \text { [39] }\end{array}$} & \multirow[t]{2}{*}{ NCT01478048 } & \multirow[t]{2}{*}{$1 / 2$} & $77^{f}$ & Elotuzumab $(10 \mathrm{mg} / \mathrm{kg})+\mathrm{VD}$ & $66 \%$ & 1-year $39 \%$, 2-year $18 \%$ & 9.7 \\
\hline & & & 75 & VD & $63 \%$ & 1 -year $33 \%$, 2-year $11 \%$ & 6.9 \\
\hline
\end{tabular}

$N$ number; ORR objective response rate; PFS progression-free survival; $R d$ lenolidomide and dexamethasone; TD thalidomide and dexamethasone; $V$ bortezomib; VD bortezomib and dexamethasone

${ }^{a}$ Thirty-four patients treated

${ }^{\mathrm{b}}$ Twenty-eight patients treated

"Median time to progression or death

${ }^{\mathrm{d} C y c l o p h o s p h a m i d e}$ was added if progressing between cycle 2 and 5 or not responding by cycle 5

'Median time to progression

fSeventy-five patients treated

The phase 2 part of the 1703 study evaluated elotuzumab (10 or $20 \mathrm{mg} / \mathrm{kg}$ through randomization) in combination with Rd for RR MM in 73 patients [27]. The median age was 62 , and patients had received $1-3$ prior lines of therapy. The median follow-up was 21.2 months for the $10 \mathrm{mg} / \mathrm{kg}$ group (36 patients) and 16.8 months for the $20 \mathrm{mg} / \mathrm{kg}$ group (37 patients). The overall ORR was $84 \%$, with $3(4 \%)$ stringent CR, 7 (10\%) CR, 31 (42\%) VGPR and 20 (27\%) PR. The ORR was 92 and $76 \%$ for the 10 and $20 \mathrm{mg} / \mathrm{kg}$ groups, respectively. The median time to initial/best response was 1.0/2.8 months for the $10 \mathrm{mg} / \mathrm{kg}$ group and $1.7 / 2.4$ months for the $20 \mathrm{mg} / \mathrm{kg}$ group. The median DOR was 34.8 and 29 months for the 10 and $20 \mathrm{mg} / \mathrm{kg}$ groups, respectively. The median time to progression (TTP) or death was 32.5 and 25.0 months for the 10 and $20 \mathrm{mg} / \mathrm{kg}$ groups, respectively, and 28.6 months overall. The safety profiles were similar between the two groups. The most common grade 3-4 AE was cytopenia. Implementation of a premedication regimen significantly reduced infusion reaction occurrence to $11 \%$ of the patients (mostly grade $1-2)$.

Compared with historical data on $\mathrm{Rd}$ [28-31], the 1703 study demonstrated that addition of elotuzumab improved the ORR (84 vs. $48-67 \%$ ) and PFS (28.6 vs. 11-18 months) in patients with RR MM [27]. The ELOQUENT-2 study directly compared the efficacy of elotuzumab plus Rd versus Rd alone for RR MM [32]. Based on results of the 1703 study, the dose of elotuzumab in this phase 3 randomized trial was $10 \mathrm{mg} / \mathrm{kg}$. In total, 646 patients were enrolled, with a median age of 66 and a median of 2 prior therapies. Seventy percent of patients had received bortezomib before, and 48 and $6 \%$ of patients had prior exposure to thalidomide and lenalidomide, respectively. About one third of patients had $17 p$ deletion. The median follow-up was 24.5 months. The ORR was $79 \%$ for the elotuzumab group (321 patients) and $66 \%$ for the control group (325 patients) (odds ratio 1.9). The PFS rate was 68 vs. $57 \%$ for the elotuzumab and control groups at 1 year and 41 vs. $27 \%$ at 2 years. The median PFS was 19.4 vs. 14.9 months for the elotuzumab and control groups (hazard ratio 0.70). The ORR and PFS in the elotuzumab group appeared inferior to those in the 1703 study, but it should be noted that patients in this trial were older, and more patients had high-risk cytogenetic profiles and coexisting illnesses $[27,32]$. Cytopenias were the most common grade 3-4 AEs and occurred at similar rates in both groups, except for a higher rate of lymphocytopenia in the elotuzumab group (77 vs. $49 \%$ ), which was likely due to lymphocyte trafficking. With mandatory premedication, infusion reaction occurrence was $10 \%$ in the elotuzumab group. Results of the ELOQUENT-2 study clearly proved the benefit of adding elotuzumab to Rd for the treatment of RR MM. Based on these data, FDA approved elotuzumab to be used in combination with lenalidomide and dexamethasone for MM patients who had received one to three prior therapies.

The ELOQUENT-1 trial, which studies Rd with or without elotuzumab for untreated MM, is currently 
ongoing. A recent phase $1 \mathrm{~b}$ trial studied the pharmacokinetics and safety of the elotuzumab plus Rd combination in 26 patients with various renal function and demonstrated that patients with severe renal impairment (creatinine clearance $[\mathrm{CrCl}]<30 \mathrm{~mL} / \mathrm{min}$, not requiring dialysis) and end-stage renal disease (requiring dialysis) had identical elotuzumab pharmacokinetics and safety profile compared with patients with normal renal function $(\mathrm{CrCl}>90 \mathrm{~mL} / \mathrm{min})$, suggesting that elotuzumab does not require dose adjustment in MM patients with renal dysfunction [33]. The combination of elotuzumab with another IMiD, thalidomide, was studied in a phase 2 trial [34]. Forty patients were enrolled, with a median age of 64 and a median of 3 prior therapies. Patients received elotuzumab in combination with thalidomide and dexamethasone (TD) and cyclophosphamide if progressing between cycle 2 and 5 or not responding by cycle 5 . Except for infusion reactions, elotuzumab caused minimal incremental toxicity when added to TD. The ORR was $40 \%$, and $63 \%$ of patients maintained response at 1 year.

The combination of elotuzumab and PIs has also been studied. A phase 1 trial studied the elotuzumab and bortezomib combination for patients with RR MM [35]. Twenty-eight patients with a median age of 63 and a median of 2 prior therapies were enrolled. During elotuzumab dose escalation ( 2.5 to $20 \mathrm{mg} / \mathrm{kg}$ ), no DLT was observed and MTD was not reached up to MPD. The most frequent grade 3-4 AEs were lymphopenia and fatigue. In 27 evaluable patients, the ORR was $48 \%$. The median TTP was 9.46 months. Compared with previous data on bortezomib monotherapy for RR MM [3, 36, 37], the elotuzumab plus bortezomib combination appeared to have better ORR (48 vs. $27-41 \%$ )

Table 2 Major ongoing clinical trials of elotuzumab

\begin{tabular}{|c|c|c|c|c|}
\hline NCT number & Title & $\mathrm{Ph}$ & $N$ & Recruitment \\
\hline NCT01335399 (ELOQUENT-1) & $\begin{array}{l}\text { Phase III study of lenalidomide and dexamethasone with or without elotuzumab } \\
\text { to treat newly diagnosed, previously untreated multiple myeloma }\end{array}$ & 3 & 750 & Active, not recruiting \\
\hline NCT02272803 & $\begin{array}{l}\text { Phase II study of lenalidomide/dexamethasone with or without elotuzumab for } \\
\text { newly diagnosed MM patients in Japan }\end{array}$ & 2 & 80 & Recruiting \\
\hline NCT01241292 & $\begin{array}{l}\text { Japanese study of BMS-901608 (Elotuzumab) in combination with lenalidomide } \\
\text { and low dose dexamethasone }\end{array}$ & 1 & 7 & Active, not recruiting \\
\hline NCT02159365 & $\begin{array}{l}\text { Study of safety of elotuzumab administered over approximately } 60 \text { min in } \\
\text { combination with lenalidomide and dexamethasone for newly diagnosed or } \\
\text { relapsed/refractory multiple myeloma patients }\end{array}$ & 2 & 76 & Active, not recruiting \\
\hline NCT01393964 & $\begin{array}{l}\text { Study of elotuzumab in combination with lenalidomide and dexamethasone in } \\
\text { subjects with multiple myeloma and various levels of renal function }\end{array}$ & 1 & 35 & Active, not recruiting \\
\hline NCT02279394 & $\begin{array}{l}\text { Trial of combination of elotuzumab and lenalidomide }+/ \text { - dexamethasone in } \\
\text { high-risk smoldering multiple myeloma }\end{array}$ & 2 & 82 & Recruiting \\
\hline NCT02420860 & $\begin{array}{l}\text { Study of elotuzumab with lenalidomide as maintenance after autologous stem } \\
\text { cell transplant (ASCT) }\end{array}$ & 2 & 100 & Recruiting \\
\hline NCT02655458 & $\begin{array}{l}\text { Elotuzumab in autologous stem cell transplantation (ASCT) and lenalidomide } \\
\text { maintenance for multiple myeloma }\end{array}$ & 1 & 15 & Recruiting \\
\hline NCT02612779 & $\begin{array}{l}\text { A study of elotuzumab in combination with pomalidomide and low dose } \\
\text { dexamethasone (EPd) in patients with multiple myeloma relapsed or } \\
\text { refractory to prior treatment with lenalidomide }\end{array}$ & 2 & 60 & Recruiting \\
\hline NCT02654132 & $\begin{array}{l}\text { Trial of pomalidomide and low-dose dexamethasone with or without elotuzumab } \\
\text { to treat refractory and relapsed and refractory multiple myeloma (ELOQUENT-3) }\end{array}$ & 2 & 121 & Recruiting \\
\hline NCT01668719 (S1211) & $\begin{array}{l}\text { Bortezomib, dexamethasone, and lenalidomide with or without elotuzumab in } \\
\text { treating patients with newly diagnosed high-risk multiple myeloma }\end{array}$ & $1 / 2$ & 122 & Recruiting \\
\hline NCT02375555 & $\begin{array}{l}\text { Study of bortezomib, lenalidomide, dexamethasone \& elotuzumab in newly } \\
\text { diagnosed MM }\end{array}$ & 2 & 40 & Recruiting \\
\hline NCT02495922 (GMMG HD6) & $\begin{array}{l}\text { A phase III trial on the effect of elotuzumab in VRD induction/consolidation } \\
\text { and lenalidomide maintenance in patients with newly diagnosed myeloma }\end{array}$ & 3 & 516 & Recruiting \\
\hline NCT02718833 & $\begin{array}{l}\text { A study of elotuzumab with pomalidomide, bortezomib, and dexamethasone in } \\
\text { relapsed multiple myeloma }\end{array}$ & 2 & 46 & Recruiting \\
\hline NCT02726581 & $\begin{array}{l}\text { Study of combinations of nivolumab, elotuzumab, pomalidomide and } \\
\text { dexamethasone in multiple myeloma }\end{array}$ & 3 & 406 & Recruiting \\
\hline NCT02252263 & $\begin{array}{l}\text { A phase I open label study of the safety and tolerability of elotuzumab } \\
\text { (BMS-901608) administered in combination with either lirilumab (BMS-986015) } \\
\text { or urelumab (BMS-663513) in subjects with multiple myeloma }\end{array}$ & 1 & 136 & Active, not recruiting \\
\hline
\end{tabular}


and TTP (9.46 vs. $6.22-7$ months). A phase 2 randomized trial compared elotuzumab in combination with bortezomib and dexamethasone (Vel/Dex) vs. Vel/Dex alone for patients with RR MM [38, 39]. In total, 152 patients were randomized, with a median age of 66 . The ORR was $66 \%$ in the elotuzumab arm (77 patients) and $63 \%$ in the control arm (75 patients). The 1-year PFS rate was 39 and $33 \%$, and 2-year PFS rate was 18 and $11 \%$, for the elotuzumab and control arm, respectively. The median PFS was 9.7 months in the elotuzumab arm and 6.9 months in the control arm. The PFS rates were lower and the PFS was shorter than those seen in the ELOQUENT-2 study in which Rd was used [32]. Nevertheless, data from this phase 2 study suggest that addition of elotuzumab to bortezomib-based therapy may provide additional benefit for patients with RR MM.

Adding elotuzumab to the IMiD/PI combination is also under investigation. The SWOG study S1211 was designed to evaluate the efficacy of adding elotuzumab to lenalidomide, bortezomib, and dexamethasone (RVd) for the front line therapy of high risk MM. In the phase 1 portion, newly diagnosed symptomatic MM patients regardless of risk were eligible. Eight patients were enrolled and six received treatment. At the time of report, all six patients had completed 8 cycles of induction therapy with elotuzumab in combination with RVd, and five had completed at least 4 cycles of maintenance therapy with dose-attenuated RVd and elotuzumab. The phase 1 safety data demonstrated that elotuzumab did not lead to major additive AEs beyond those known for RVd [40]. The phase 2 part of the trial is ongoing and will provide the efficacy data. Some additional ongoing trials of elotuzumab in combination with IMiDs, PIs and/or other novel agents are listed in Table 2.

\section{Conclusions}

Elotuzumab has demonstrated excellent efficacy and safety profiles when combined with an IMiD or PI for the treatment of RR MM. There was only limited data on single agent elotuzumab for RR MM, with only three patients treated at the FDA approved dose in the initial phase 1 study [23]. Further investigations should be done to evaluate its efficacy when used alone. Ongoing clinical trials will further define the efficacy of elotuzumab with IMiD or PI combinations in both untreated and RR MM patients and evaluate the four drug combination (elotuzumab, IMiD, PI, and corticosteroid) for MM treatment. Importantly, so far, there has been no data demonstrating the efficacy of elotuzumab in lenalidomide-refractory patients. How to overcome this significant limitation requires further investigation. The use of elotuzumab as part of induction and/or maintenance therapy is under investigation. Whether combining elotuzumab with chemotherapy is beneficial in MM needs to be studied. Combining elotuzumab with daratumumab is worth investigating. Hitting CD38 and SLAMF7 simultaneously may provide a higher MM cell killing efficacy and may overcome potential resistance to either agent. Daratumumab reduces NK cell levels, and perhaps combining daratumumab with elotuzumab may be effective in overcoming this effect. Combining elotuzumab with other immunotherapies such as anti-PD1 antibodies, anti-KIR antibodies, and CD137 agonizing antibodies are under investigation in clinical trials already. AntiPD1 therapies may activate T cell-mediated MM cell killing mechanisms, adding to the NK cell-mediated anti-myeloma activities. Activating the CD137 receptor or blocking the KIR-mediated inhibitory signaling can modulate NK cell-mediated ADCC, and combining elotuzumab with these agents may lead to enhanced MM cell killing by ADCC [19, 20]. With expanding options available, when and how to use each agent will be an ever-evolving question. Related biomarkers on response and prognosis are to be studied. Whether elotuzumab, alone or in combination with other regimens, provides a different efficacy and safety profile in a specific population requires further study $[30,41]$.

\section{Abbreviations \\ ADCC, antibody dependent cell-mediated cytotoxicity; $A E$, adverse event; BMSC, bone marrow stromal cells; CR, complete response; DLT, dose-limiting toxicity; DOR, duration of response; IMiD, immunomodulatory drug; MM, multiple myeloma; MPD, maximum planned dose; MTD, maximum tolerated dose; NK, natural killer; ORR, objective response rate; OS, overall survival; PBMC, peripheral blood mononuclear cell; PFS, progression-free survival; $\mathrm{Pl}$, proteasome inhibitors; PR, partial response; Rd, lenalidomide and dexamethasone; RR, relapsed or refractory; RVd, lenalidomide, bortezomib and dexamethasone; SD, stable disease; TD, thalidomide and dexamethasone; TTP, time to progression; Vel/Dex, bortezomib and dexamethasone; VGPR, very good partial response}

\section{Acknowledgements}

Yucai Wang is a recipient of Chinese American Hematologists and

Oncologists (CAHON) Young Investigator Award (YIA). The authors would like to thank Steve and Nancy Fox Research Fund for their generous support in lymphoma and myeloma research.

\section{Funding \\ None}

\section{Availability of data and materials}

The dataset supporting the conclusions of this article is included within the article.

\section{Authors' contributions}

MW designed the study. YW and LS drafted the manuscript. YW designed and finalized the figure. DS and MW participated in the manuscript

preparation and revisions. All authors read and approved final manuscript.

Competing interests

The authors declare that they have no competing interests. 


\section{Consent for publication}

Not applicable.

\section{Ethics approval and consent to participate}

Not applicable.

\section{Author details}

'Department of Medicine, Rutgers New Jersey Medical School, Newark, NJ, USA. ${ }^{2}$ Division of Multiple Myeloma, John Theurer Cancer Center, Hackensack University Medical Center, Hackensack, NJ, USA. ${ }^{3}$ Department of Lymphoma/ Myeloma, Division of Cancer Medicine, The University of Texas M. D. Anderson Cancer Center, 1515 Holcombe Blvd., Unit 429, Houston, TX 77030, USA.

Received: 24 May 2016 Accepted: 7 July 2016

Published online: 15 July 2016

\section{References}

1. Singhal S, Mehta J, Desikan R, Ayers D, Roberson P, Eddlemon P, Munshi N, Anaissie E, Wilson C, Dhodapkar M, et al. Antitumor activity of thalidomide in refractory multiple myeloma. N Engl J Med. 1999;341(21):1565-71.

2. Richardson PG, Schlossman RL, Weller E, Hideshima T, Mitsiades C, Davies F, LeBlanc R, Catley LP, Doss D, Kelly K, et al. Immunomodulatory drug CC-5013 overcomes drug resistance and is well tolerated in patients with relapsed multiple myeloma. Blood. 2002;100(9):3063-7.

3. Richardson PG, Barlogie B, Berenson J, Singhal S, Jagannath S, Irwin D, Rajkumar SV, Srkalovic G, Alsina M, Alexanian R, et al. A phase 2 study of bortezomib in relapsed, refractory myeloma. N Engl J Med. 2003;348(26):2609-17.

4. Kumar SK, Dispenzieri A, Lacy MQ, Gertz MA, Buadi FK, Pandey S, Kapoor P, Dingli D, Hayman SR, Leung $N$, et al. Continued improvement in survival in multiple myeloma: changes in early mortality and outcomes in older patients. Leukemia. 2014;28(5):1122-8.

5. Kumar SK, Lee JH, Lahuerta JJ, Morgan G, Richardson PG, Crowley J, Haessler J, Feather J, Hoering A, Moreau P, et al. Risk of progression and survival in multiple myeloma relapsing after therapy with IMiDs and bortezomib: a multicenter international myeloma working group study. Leukemia. 2012:26(1):149-57

6. El-Amm J, Tabbara IA. Emerging therapies in multiple myeloma. Am J Clin Oncol. 2015:38(3):315-21.

7. Hsi ED, Steinle R, Balasa B, Szmania S, Draksharapu A, Shum BP, Huseni M, Powers D, Nanisetti A, Zhang Y, et al. CS1, a potential new therapeutic antibody target for the treatment of multiple myeloma. Clin Cancer Res. 2008; 14(9):2775-84.

8. Veillette A, Guo H. CS1, a SLAM family receptor involved in immune regulation, is a therapeutic target in multiple myeloma. Crit Rev Oncol Hematol. 2013:88(1):168-77.

9. Liu YC, Szmania S, van Rhee F. Profile of elotuzumab and its potential in the treatment of multiple myeloma. Blood Lymphat Cancer. 2014;2014(4):15-27.

10. Bouchon A, Cella M, Grierson HL, Cohen Jl, Colonna M. Activation of NK cell-mediated cytotoxicity by a SAP-independent receptor of the CD2 family. J Immunol. 2001;167(10):5517-21.

11. Kumaresan PR, Lai WC, Chuang SS, Bennett M, Mathew PA. CS1, a novel member of the CD2 family, is homophilic and regulates NK cell function. Mol Immunol. 2002;39(1-2):1-8.

12. Cruz-Munoz ME, Dong Z, Shi X, Zhang S, Veillette A. Influence of CRACC, a SLAM family receptor coupled to the adaptor EAT-2, on natural killer cell function. Nat Immunol. 2009;10(3):297-305.

13. Tai YT, Dillon M, Song W, Leiba M, Li XF, Burger P, Lee Al, Podar K, Hideshima T, Rice AG, et al. Anti-CS1 humanized monoclonal antibody HuLuc63 inhibits myeloma cell adhesion and induces antibody-dependent cellular cytotoxicity in the bone marrow milieu. Blood. 2008;112(4):1329-37.

14. Tai YT, Soydan E, Song W, Fulciniti M, Kim K, Hong F, Li XF, Burger P, Rumizen MJ, Nahar S, et al. CS1 promotes multiple myeloma cell adhesion, clonogenic growth, and tumorigenicity via c-maf-mediated interactions with bone marrow stromal cells. Blood. 2009;113(18):4309-18.

15. Rice A, Dillon M, van Abbema A, Jesaitis L, Wong M, Lawson S, Liu G, Zhang $Y$, Powers D, Rhodes $S$, et al. Eradication of tumors in pre-clinical models of multiple myeloma by anti-CS1 monoclonal antibody HuLuc63: mechanism of action studies. Blood. 2006;108(11):3503-3.

16. Collins SM, Bakan CE, Swartzel GD, Hofmeister CC, Efebera YA, Kwon H, Starling GC, Ciarlariello D, Bhaskar S, Briercheck EL, et al. Elotuzumab directly enhances NK cell cytotoxicity against myeloma via CS1 ligation: evidence for augmented NK cell function complementing ADCC. Cancer Immunol Immunother. 2013;62(12):1841-9.

17. van Rhee F, Szmania SM, Dillon M, van Abbema AM, Li X, Stone MK, Garg TK, Shi J, Moreno-Bost AM, Yun R, et al. Combinatorial efficacy of anti-CS1 monoclonal antibody elotuzumab (HuLuc63) and bortezomib against multiple myeloma. Mol Cancer Ther. 2009;8(9):2616-24.

18. Balasa B, Yun R, Belmar NA, Fox M, Chao DT, Robbins MD, Starling GC, Rice AG. Elotuzumab enhances natural killer cell activation and myeloma cell killing through interleukin-2 and TNF-alpha pathways. Cancer Immunol Immunother. 2015:64(1):61-73.

19. Sola C, Blery M, Bonnafous C, Bonnet E, Fuseri N, Graziano RF, Morel Y, André P. Lirilumab enhances anti-tumor efficacy of elotuzumab. Blood. 2014;124(21):4711-1.

20. Robbins M, Jure-Kunkel M, Dito G, Andre P, Zhang H-f, Bezman N, Graziano RF. Effects of IL-21, KIR blockade, and CD137 agonism on the non-clinical activity of elotuzumab. Blood. 2014;124(21):4717-7.

21. Garg TK, Szmania S, Shi J, Stone K, Moreno-Bost A, Malbrough P, Campana D, Barlogie B, Afar D, van Rhee F. Ex vivo activated natural killer (NK) cells from myeloma patients kill autologous myeloma and killing is enhanced by elotuzumab. Blood. 2008;112(11):3666-6.

22. Szmania S, Lapteva N, Garg T, Greenway A, Lingo J, Nair B, Stone K, Woods E, Khan J, Stivers J, et al. Ex vivo-expanded natural killer cells demonstrate robust proliferation in vivo in high-risk relapsed multiple myeloma patients. J Immunother. 2015;38(1):24-36.

23. Zonder JA, Mohrbacher AF, Singhal S, van Rhee F, Bensinger WI, Ding H, Fry J, Afar DE, Singhal AK. A phase 1, multicenter, open-label, dose escalation study of elotuzumab in patients with advanced multiple myeloma. Blood. 2012;120(3):552-9.

24. Garcia MK, Cohen L, Guo Y, Zhou Y, You B, Chiang J, Orlowski RZ, Weber D, Shah J, Alexanian R, et al. Electroacupuncture for thalidomide/bortezomibinduced peripheral neuropathy in multiple myeloma: a feasibility study. J Hematol Oncol. 2014;7:41

25. Wang Y, Yang F, Shen Y, Zhang W, Wang J, Chang VT, Andersson BS, Qazilbash MH, Champlin RE, Berenson JR, et al. Maintenance therapy with immunomodulatory drugs in multiple myeloma:a meta-analysis and systematic review. J Natl Canc Inst. 2016;108(3):djv342.

26. Lonial S, Vij R, Harousseau JL, Facon T, Moreau P, Mazumder A, Kaufman JL, Leleu X, Tsao LC, Westland C, et al. Elotuzumab in combination with lenalidomide and low-dose dexamethasone in relapsed or refractory multiple myeloma. J Clin Oncol. 2012;30(16):1953-9.

27. Richardson PG, Jagannath S, Moreau P, Jakubowiak AJ, Raab MS, Facon T, Vij $R$, White D, Reece DE, Benboubker $L$, et al. Elotuzumab in combination with lenalidomide and dexamethasone in patients with relapsed multiple myeloma: final phase 2 results from the randomised, open-label, phase $1 \mathrm{~b}-2$ dose-escalation study. Lancet Haematol. 2015;2(12):e516-527.

28. Dimopoulos M, Spencer A, Attal M, Prince HM, Harousseau JL, Dmoszynska A, San Miguel J, Hellmann A, Facon T, Foa R, et al. Lenalidomide plus dexamethasone for relapsed or refractory multiple myeloma. $\mathrm{N}$ Engl J Med. 2007;357(21):2123-32.

29. Weber DM, Chen C, Niesvizky R, Wang M, Belch A, Stadtmauer EA, Siegel D, Borrello I, Rajkumar SV, Chanan-Khan AA, et al. Lenalidomide plus dexamethasone for relapsed multiple myeloma in North America. N Engl J Med. 2007;357(21):2133-42.

30. Hou J, Du X, Jin J, Cai Z, Chen F, Zhou DB, Yu L, Ke X, Li X, Wu D, et al. A multicenter, open-label, phase 2 study of lenalidomide plus low-dose dexamethasone in Chinese patients with relapsed/refractory multiple myeloma: the MM-021 trial. J Hematol Oncol. 2013;6:41.

31. Stewart AK, Rajkumar SV, Dimopoulos MA, Masszi T, Spicka I, Oriol A, Hajek R, Rosinol L, Siegel DS, Mihaylov GG, et al. Carfilzomib, lenalidomide, and dexamethasone for relapsed multiple myeloma. N Engl J Med. 2015:372(2):142-52.

32. Lonial S, Dimopoulos M, Palumbo A, White D, Grosicki S, Spicka I, Walter-Croneck A, Moreau P, Mateos MV, Magen H, et al. Elotuzumab therapy for relapsed or refractory multiple myeloma. N Engl J Med. 2015;373(7):621-31.

33. Berdeja J, Jagannath S, Zonder J, Badros A, Kaufman JL, Manges R, Gupta M, Tendolkar A, Lynch M, Bleickardt E, et al. Pharmacokinetics and safety of elotuzumab combined with lenalidomide and dexamethasone in patients with multiple myeloma and various levels of renal impairment: results of a phase Ib study. Clin Lymphoma Myeloma Leuk. 2016;16(3):129-38. 
34. Mateos MV, Granell M, Oriol Rocafiguera A, Martinez Lopez J, Blade J, Hernandez MT, Martin Sanchez J, Gironella M, Lynch M, Bleickardt E, et al. A phase II single-arm safety study of elotuzumab in combination with thalidomide and low dose dexamethasone in patients with relapsed and/or refractory multiple myeloma. Haematologica. 2014;99(s1):361-2.

35. Jakubowiak AJ, Benson DM, Bensinger W, Siegel DS, Zimmerman TM, Mohrbacher A, Richardson PG, Afar DE, Singhal AK, Anderson KC. Phase I trial of anti-CS1 monoclonal antibody elotuzumab in combination with bortezomib in the treatment of relapsed/refractory multiple myeloma. J Clin Oncol. 2012;30(16):1960-5.

36. Richardson PG, Sonneveld P, Schuster MW, Irwin D, Stadtmauer EA, Facon T, Harousseau JL, Ben-Yehuda D, Lonial S, Goldschmidt H, et al. Bortezomib or high-dose dexamethasone for relapsed multiple myeloma. N Engl J Med. 2005;352(24):2487-98.

37. Orlowski RZ, Nagler A, Sonneveld P, Blade J, Hajek R, Spencer A, San Miguel J, Robak T, Dmoszynska A, Horvath N, et al. Randomized phase III study of pegylated liposomal doxorubicin plus bortezomib compared with bortezomib alone in relapsed or refractory multiple myeloma: combination therapy improves time to progression. J Clin Oncol. 2007;25(25):3892-901.

38. Palumbo A, Offidani M, Pégourie B, De La Rubia J, Garderet L, Laribi K, Bosi A, Marasca R, Laubach JP, Mohrbacher A, et al. Elotuzumab plus bortezomib and dexamethasone versus bortezomib and dexamethasone in patients with relapsed/refractory multiple myeloma: 2-year follow-up. Blood. 2015;126(23):510-0.

39. Jakubowiak A, Offidani M, Pegourie B, De La Rubia J, Garderet L, Laribi K, Bosi A, Marasca R, Laubach J, Mohrbacher A, et al. Randomized phase 2 study: elotuzumab plus bortezomib/dexamethasone vs bortezomib/ dexamethasone for relapsed/refractory MM. Blood. 2016;127(23):2833-40.

40. Usmani SZ, Sexton R, Ailawadhi S, Shah JJ, Valent J, Rosenzweig M, Lipe B, Zonder JA, Fredette $\mathrm{S}$, Durie $\mathrm{B}$, et al. Phase I safety data of lenalidomide, bortezomib, dexamethasone, and elotuzumab as induction therapy for newly diagnosed symptomatic multiple myeloma: SWOG S1211. Blood Cancer J. 2015:5:e334.

41. Gupta N, Goh YT, Min CK, Lee JH, Kim K, Wong RS, Chim CS, Hanley MJ, Yang $\mathrm{H}$, Venkatakrishnan $\mathrm{K}$, et al. Pharmacokinetics and safety of ixazomib plus lenalidomide-dexamethasone in Asian patients with relapsed/refractory myeloma: a phase 1 study. J Hematol Oncol. 2015;8:103.

\section{Submit your next manuscript to BioMed Central and we will help you at every step:}

- We accept pre-submission inquiries

- Our selector tool helps you to find the most relevant journal

- We provide round the clock customer support

- Convenient online submission

- Thorough peer review

- Inclusion in PubMed and all major indexing services

- Maximum visibility for your research

Submit your manuscript at www.biomedcentral.com/submit

) Biomed Central 